\title{
Radiation-induced apoptosis in developing mouse retina exhibits dose-dependent requirement for ATM phosphorylation of p53
}

\author{
HL Borges ${ }^{1,2}$, C Chao ${ }^{1}$, Y Xu ${ }^{1}$, R Linden ${ }^{2}$ and JYJ Wang ${ }^{*, 1}$ \\ 1 Division of Biological Sciences, University of California, San Diego, 9500 \\ Gilman Drive, La Jolla, CA 92093-0322, USA; \\ 2 Instituto de Biofísica Carlos Chagas Filho, UFRJ, Centro de Ciências da \\ Saúde, bloco G, Cidade Universitária, Rio de Janeiro 21949-900, Brazil \\ * Corresponding author: JYJ Wang, Division of Biological Sciences, University of \\ California, San Diego, 9500 Gilman Drive, La Jolla, CA 92093-0322, USA. \\ Tel: + 858534 6253; Fax: + 858822 2002; E-mail: jywang@ucsd.edu
}

Received 25.9.03; revised 23.10.03; accepted 23.10.03; published online 30.1.04 Edited by Dr T Ferguson

\begin{abstract}
lonizing radiation (IR) induces DNA breakage to activate cell cycle checkpoints, DNA repair, premature senescence or cell death. A master regulator of cellular responses to IR is the ATM kinase, which phosphorylates a number of downstream effectors, including p53, to inhibit cell cycle progression or to induce apoptosis. ATM phosphorylates p53 directly at Ser15 (Ser18 of mouse p53) and indirectly through other kinases. In this study, we examined the role of ATM and p53 Ser18 phosphorylation in IR-induced retinal apoptosis of neonatal mice. Whole-body irradiation with 2 Gy IR induces apoptosis of postmitotic and proliferating cells in the neonatal retinas. This apoptotic response requires ATM, exhibits p53-haploid insufficiency and is defective in mice with the p53S18A allele. At a higher dose of $14 \mathrm{~Gy}$, retinal apoptosis still requires ATM and p53 but can proceed without Ser18 phosphorylation. These results suggest that ATM activates the apoptotic function of p53 in vivo through alternative pathways depending on IR dose.

Cell Death and Differentiation (2004) 11, 494-502.

doi:10.1038/sj.cdd.4401366

Published online 30 January 2004
\end{abstract}

Keywords: ataxia telangiectasia; knockout mice; neuroblast; p21Cip1; UCN-01

Abbreviations: IR, ionizing radiation; GCL, ganglion cell layer; INLi, inner nuclear layer incipient; NBL, neuroblastic layer; CNS, central nervous system; PCNA, proliferating cell nuclear antigen; BrdU, bromo-deoxy-uridine; PDTC, pyrrolidinedithiocarbamate; $E$, embryonic day; $P$, postnatal day

\section{Introduction}

In response to ionizing radiation (IR)-induced DNA damage, cell cycle checkpoints and DNA repair are activated to protect the genome.$^{1-3}$ If the damage is properly repaired, irradiated cells can resume proliferation and this is measured by the IR dose-dependent 'clonogenic survival'. With increasing dosage of IR, clonogenic survival is decreased exponentially due to three forms of cell death, that is, apoptosis, necrosis or 'mitotic death', a phenotype also described in the literature as 'premature senescence'. ${ }^{3-5}$ With cultured fibroblasts, loss of clonogenic survival is mostly due to mitotic death/senescence. $^{4}$ By contrast, regenerating or developing tissues undergo apoptosis in response to IR. For example, the developing central nervous system (CNS), including the retinas, is hypersensitive to IR. The developing retina undergoes apoptosis at IR doses as low as $0.5-2$ Gy and, thus, provides an appropriate in vivo system to investigate the IRinduced apoptotic response. ${ }^{6}$

We have previously characterized the retinal apoptotic response to IR in newborn rats, ${ }^{6}$ and found it to involve at least two types of cells. An early wave of apoptosis at $6 \mathrm{~h}$ post-IR involved postmitotic and proliferating cells that were not in S-phase. A second wave of apoptosis at $24 \mathrm{~h}$ post-IR involved proliferating cells, including those in S-phase during IR. The antioxidant pyrrolidinedithiocarbamate (PDTC) prevented the first but not the second wave of apoptosis. To examine the role of DNA-damage signaling molecules in this apoptotic response to IR, we expanded the study to neonatal mice with mutations in Atm and Trp53 (the mouse p53 gene).

ATM is the gene mutated in ataxia telangiectasia (A-T), an autosomal recessive disorder characterized by hypersensitivity to IR, cancer susceptibility, sterility, progressive cerebellar ataxia and premature aging. ${ }^{7}$ ATM has a central role in regulating the cellular response to IR. ${ }^{8-10}$ The hypersensitivity of A-T fibroblasts and lymphoblasts to $I R$ is attributed to defects in cell cycle checkpoints and DNA repair. ${ }^{8,9}$ Therefore, ATM has a protective role in these cell types. However, ATM also regulates the apoptotic response to IR. This was first demonstrated in the developing CNS of the mouse. Irradiation of neonatal mice with $14 \mathrm{~Gy}$ of IR induced apoptosis in the CNS, and the apoptotic response was compromised in $\mathrm{Atm}^{-1-}$ mice. ${ }^{11}$ In addition, the ectopic apoptosis in the developing CNS of DNA-ligase 4 (Lig4)deficient mice could be rescued by the knockout of Atm. ${ }^{12,13}$ These results suggest that ATM activates apoptosis in neural lineage following DNA damage.

ATM encodes a large nuclear protein that contains a PI3 kinase-related domain, and the ATM kinase activity is rapidly and maximally activated at IR dose as low as 0.5 Gy. ${ }^{14}$ ATM phosphorylates a number of proteins, including NBS-1, BRCA1, CHK2, p53, MDM2 and C-ABL. ${ }^{8,15-19}$ Among the ATM substrates, p53 and c-ABL have been shown to activate apoptosis in response to DNA damage..$^{20,21}$ In particular, p53 plays an essential role in IR-induced apoptosis of thymocytes and immature neurons. ${ }^{12,22-24}$ ATM phosphorylates p53 directly at Ser15, a site conserved in mouse p53 (Ser18). ${ }^{25}$ Phosphorylation of p53 at Ser15 
has been shown to play a role in activating its transactivation function. ${ }^{26}$ ATM also stimulates other kinases that phosphorylate p53 at other sites. For example, ATM phosphorylates $\mathrm{CHK} 2$ to promote the activation of its activity, which phosphorylates p53 at Ser20 (Ser23 in mouse p53). ${ }^{9,26,27}$ ATM can further activate p53 by phosphorylating MDM2 and neutralizing its ability to inhibit p53. ${ }^{18}$ The current evidence, mostly derived from experiments with cultured cells, suggests that each of these ATM-regulated pathways can contribute to the activation of p53, leading to cell cycle arrest or apoptosis.

In this study, we examined the role of Atm, Trp53 and Ser18 phosphorylation of p53 in IR-induced retinal apoptosis of neonatal mice. With this in vivo system, we found Atm and two alleles of Trp53 to be required for 2 Gy of IR to induce apoptosis of both postmitotic and proliferating cells in the developing retina. Mutation of Ser18 to Ala in p53 impaired the retinal apoptotic response to $2 \mathrm{~Gy}$ of IR. However, the Ser18Ala mutation does not affect retinal apoptosis induced by $14 \mathrm{~Gy}$ of IR, although Atm and Trp53 are still required. These results suggest an IR dose-dependent regulation of apoptosis through ATM and p53.

\section{Results}

Retinas from neonatal mice contain cells that are hypersensitive to IR and undergo apoptosis after 2 Gy of irradiation, a dose well tolerated by most other cell types. At this stage of development, the retina is composed of three layers of cells: a ganglion cell layer (GCL), an incipient inner nuclear layer (INLi) and a neuroblastic layer (NBL). The latter contains both proliferating neuroblasts and undifferentiated postmitotic cells. $^{28,29}$ Proliferating neuroblasts in the NBL undergo interkinetic nuclear migration with S-phase in the inner portion and $\mathrm{M}$-phase at the outer edge (Figure 1a). ${ }^{28,30,31} \mathrm{IR}$-induced apoptosis is restricted to the NBL and involves cells both in the proliferating (positive for PCNA) and postmitotic (negative for PCNA) compartments (Figure 1b, $c$ and f). As early as 4-6h post-2Gy of IR, a first wave of terminal deoxynucleotidyl transferase-mediated dUTP nick-end labeling (TUNEL ${ }^{+}$) nuclei appeared in the outer NBL, with about $40 \%$ being $\mathrm{PCNA}^{+}$(Figure 1b, $c$ and $\mathrm{f}$ ). A second wave of TUNEL ${ }^{+}$cells appeared at $24 \mathrm{~h}$ post-IR in the inner NBL, with around $80 \%$ being $\mathrm{PCNA}^{+}$(Figure 1b, $\mathrm{c}$ and f). By pulse labeling the mice with BrdU for $1 \mathrm{~h}$ prior to IR, we found the early apoptotic cells

a

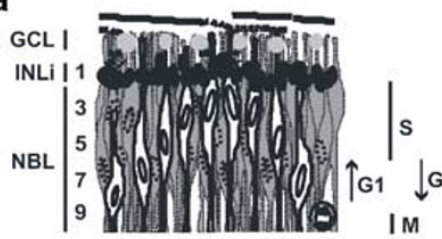

d

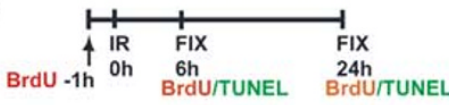

b
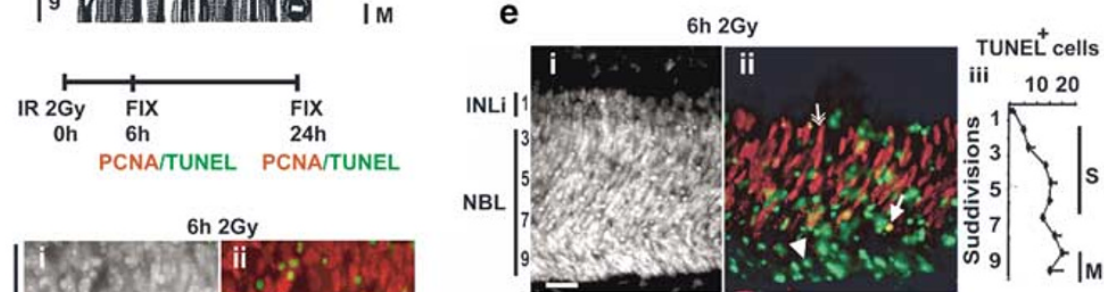

6h 2Gy
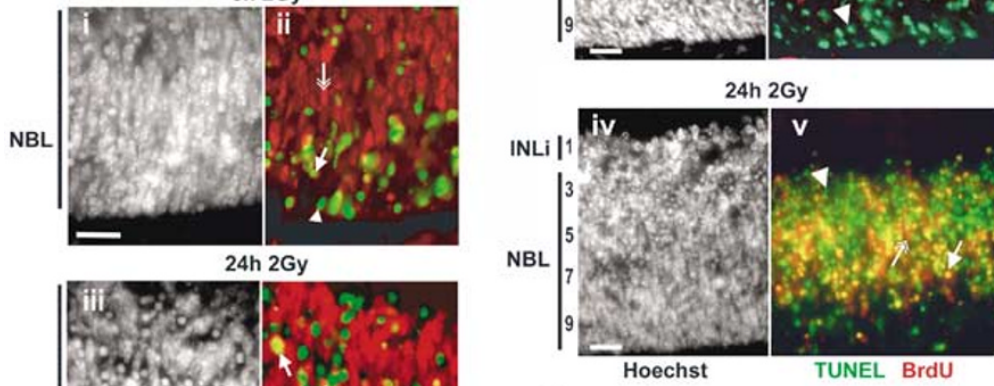

TUNEL cells
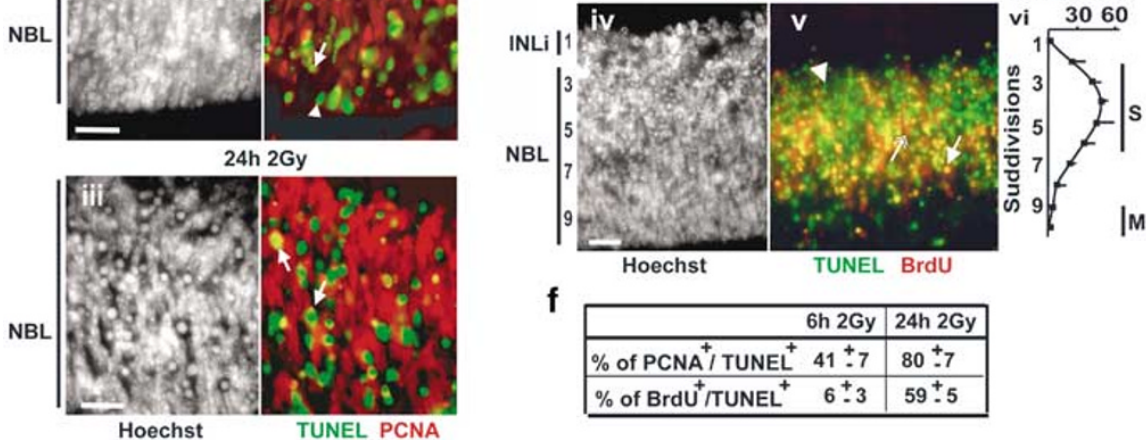

Im

Figure 1 IR induces two waves of apoptosis in the retinas of newborn mice. (a) Diagram of cell layers in the developing retina and the interkinetic nuclear migration (cell cycle-related nuclear migration). Proliferating neuroblasts (white cells) and the nuclear migration are shown along the phases of the cell cycle as indicated with the vertical bars and arrows on the right. Numbers on the left (1-9) represent subfields in which TUNEL ${ }^{+}$cells were counted in e. GCL, ganglion cell layer; INLi, inner nuclear layer incipient; NBL, neuroblastic layer. (b) Experimental protocol for results shown in (c). Photomicrographs of retinal transverse sections, $6 \mathrm{~h}$ (i, ii) and $24 \mathrm{~h}$ (iii, iv) post-IR: i, iii, bisbenzimide (Hoechst staining) (white); ii, iv, TUNEL assay (green) plus immunohistochemistry for PCNA (red). Arrowhead points to a typical TUNEL nucleus, arrows point to nuclei positive for TUNEL and PCNA, double arrow points to a PCNA ${ }^{+}$cell with normal morphology. (d) Experimental protocol for results shown in (e). Retinal sections collected at $6 \mathrm{~h}$ (i, ii) and $24 \mathrm{~h}$ (iv, v) post-IR: i, iv, Hoechst staining (white); ii, v, TUNEL (green) plus BrdU (red) staining. Graphs (iii, vi) were generated by counting the distribution of TUNEL ${ }^{+}$cells in the subfields of the INLi $+N B L$ layers at $6 \mathrm{~h}$ (iii) and $24 \mathrm{~h}$ (vi) after IR. Arrowheads point to a typical TUNEL ${ }^{+}$ nucleus, arrows point to nuclei positive for TUNEL and BrdU, double arrows point to BrdU ${ }^{+}$cells with normal morphology. (f) Summary of the percentage of doublepositive cells (TUNEL plus PCNA or TUNEL plus BrdU) relative to TUNEL ${ }^{+}$cells. Scale bar $=20 \mu \mathrm{m}$ 
to be mostly $\mathrm{BrdU}^{-}$, whereas $50-60 \%$ of the apoptotic cells at $24 \mathrm{~h}$ were labeled with BrdU (Figure 1d, e and f). Thus, 2 Gy of IR induces apoptosis in two temporally and spatially distinctive waves: a group of postmitotic cells and non-S-phase proliferating $\left(\mathrm{PCNA}^{+}\right)$cells die rapidly, followed by death of proliferating cells including those that were irradiated during S-phase. This temporal and spatial response to low-dose IR is similar to apoptosis observed in the developing retinas of neonatal rats. ${ }^{6}$
The apoptotic response to IR was significantly reduced in retinas from neonatal $\mathrm{Atm}^{-1-}$ mice, when compared to the $\mathrm{Atm}^{+/+}$and $\mathrm{Atm}^{+/-}$littermates (Figure 2a, Table 1). Apoptosis was not generally impaired in the developing retinas of $\mathrm{Atm}^{-1-}$ mice, because ex vivo culture in $1 \mu \mathrm{M}$ $\mathrm{UCN}-01$ raised the level of TUNEL ${ }^{+}$nuclei in irradiated $\mathrm{Atm}^{-1}$ retinas to a level similar to that of the irradiated $\mathrm{Atm}^{+/+}$ retinas (Figure $2 \mathrm{~b}$ ). The residual apoptotic response in $\mathrm{Atm}^{-1-}$ retinas at 6 and $24 \mathrm{~h}$ post-IR exhibited the same two-wave

a
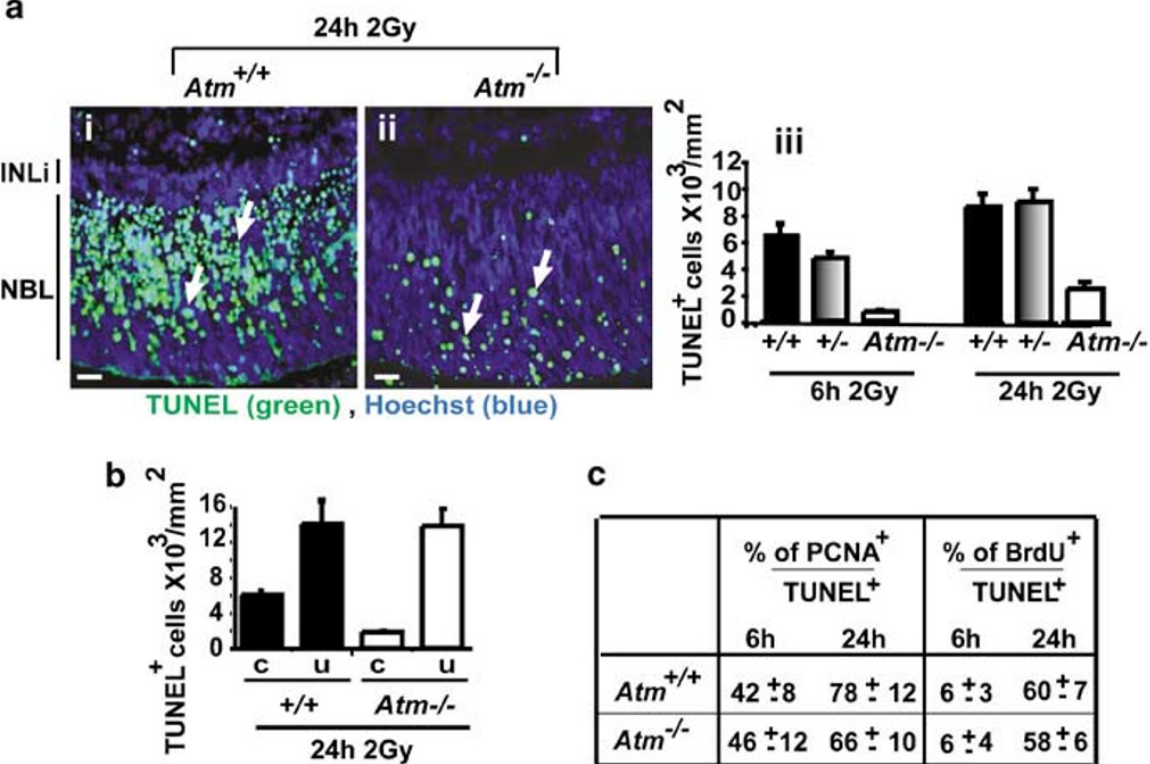

C

\begin{tabular}{|c|c|c|c|c|}
\hline & \multicolumn{2}{|c|}{$\% \frac{\text { of } \mathrm{PCNA}^{+}}{\text {TUNEL }^{+}}$} & \multicolumn{2}{|c|}{$\frac{\% \text { of } \mathrm{BrdU}^{+}}{\text {TUNEL }^{+}}$} \\
\hline & $6 \mathrm{~h}$ & $24 \mathrm{~h}$ & $6 \mathrm{~h}$ & $24 \mathrm{~h}$ \\
\hline $\mathrm{Atm}^{+/+}$ & $42 \pm 8$ & $78 \pm 12$ & $6 \pm 3$ & $60 \pm 7$ \\
\hline $\mathrm{Atm}^{-/-}$ & $46 \pm 12$ & $66 \pm 10$ & $6 \pm 4$ & $58 \pm 6$ \\
\hline
\end{tabular}

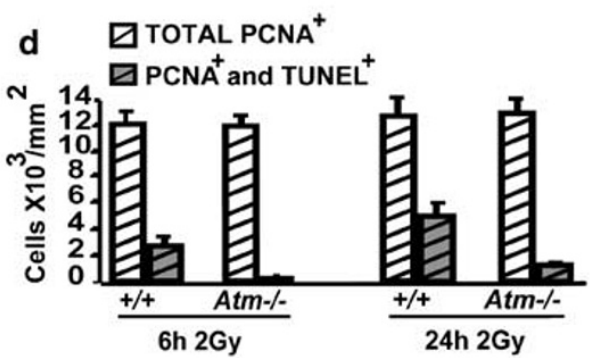

\begin{tabular}{c|cc}
\multicolumn{3}{r}{$\%$ of TUNEL } \\
& $6 \mathrm{~h}$ & $24 \mathrm{PCNA}$ \\
\hline Atm $^{+/+}$ & $15 \pm 3$ & $35 \pm 4$ \\
\hline Atm $^{-/-}$ & $1 \pm 0$ & $6 \pm 1$ \\
\hline
\end{tabular}
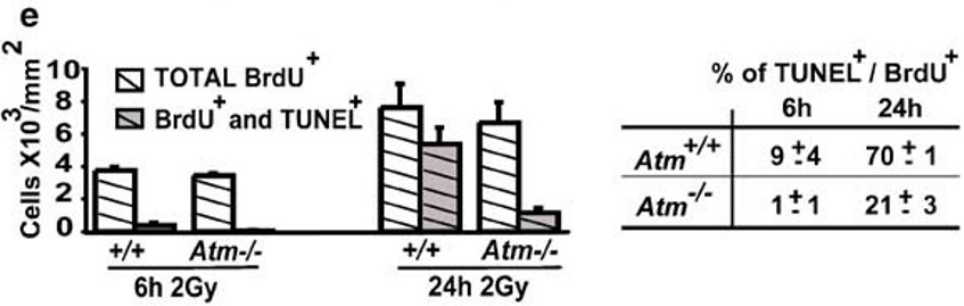

Figure 2 Atm is required for 2 Gy IR to induce apoptosis. (a) Photomicrographs of retinal sections processed for TUNEL assay (green labeling, indicated by arrows) and counterstained with Hoechst (blue labeling), $24 \mathrm{~h}$ after $2 \mathrm{~Gy}$ from $+/+$ (i) and $\mathrm{Atm}^{-1-}$ (ii) littermates. (iii) Quantification of TUNEL ${ }^{+}$cells in retinas from P1 to P3 mice, 6 and $24 \mathrm{~h}$ post-2 Gy, with the following genotypes: Atm ${ }^{+1+}$ (black bars), Atm ${ }^{+l-}$ (gray bars) and Atm $^{-1-}$ (white bars). (b) Quantification of TUNEL ${ }^{+}$cells in retinal explants from irradiated P1 littermates (2 Gy). Retinal explants were kept in the control medium (c) or in the presence of $1 \mu \mathrm{M}$ of UCN-01 (u) for $24 \mathrm{~h}$. (c) Summary of the percentage of double-positive cells (TUNEL plus PCNA or TUNEL plus BrdU) relative to TUNEL ${ }^{+}$cells in retinas from irradiated Atm ${ }^{+/+}$and Atm $^{-l-}$ littermates. (d) Quantification of PCNA ${ }^{+}$cells (hatched white bars), double-positive cells (PCNA plus TUNEL, hatched gray bars) and the percentage of double-positive cells (TUNEL plus PCNA) relative to PCNA ${ }^{+}$cells at 6 and $24 \mathrm{~h}$ after $2 \mathrm{~Gy} \mathrm{in} \mathrm{Atm}^{+1+}$ and $\mathrm{Atm}^{-l-}$ littermates. (e) Quantification of BrdU ${ }^{+}$cells (hatched white bars), doublepositive cells (BrdU plus TUNEL, hatched gray bars) and the percentage of double-positive cells (TUNEL plus BrdU) relative to BrdU ${ }^{+}$cells at 6 and $24 \mathrm{~h}$ after $2 \mathrm{~Gy}$ $\mathrm{Atm}^{+/+}$and $\mathrm{Atm}^{-1-}$ littermates 
characteristics as the $\mathrm{Atm}^{+/+}$retinas (Figure $2 \mathrm{a}$ and $\mathrm{c}$ ). The total number of $\mathrm{PCNA}^{+}$or $\mathrm{BrdU}^{+}$cells were similar between the $\mathrm{Atm}^{+1+}$ and $\mathrm{Atm}^{-1-}$ retinas, but a much lower fraction of these proliferating neuroblasts underwent apoptosis in the $\mathrm{Atm}^{-1-}$ genetic background (Figure $2 \mathrm{~d}$ and e). We also performed BrdU pulse labeling of the whole animal after irradiation. Cells dying at $6 \mathrm{~h}$ post-IR did not incorporate BrdU given at $3.5 \mathrm{~h}$ post-IR (Figure 3 ), consistent with the conclusion that postmitotic cells and $\mathrm{PCNA}^{+}$cells not in Sphase were dying early. Cells dying at $24 \mathrm{~h}$ post-IR incorporated BrdU given at $21.5 \mathrm{~h}$ post-IR (Figure 3 ), showing the second wave of death to involve actively cycling cells. Again, the level of BrdU labeling was similar between $\mathrm{Atm}^{+/+}$and $\mathrm{Atm}^{-1-}$ retinas, but fewer $\mathrm{BrdU}^{+}$cells died in the $\mathrm{Atm}^{-1-}$
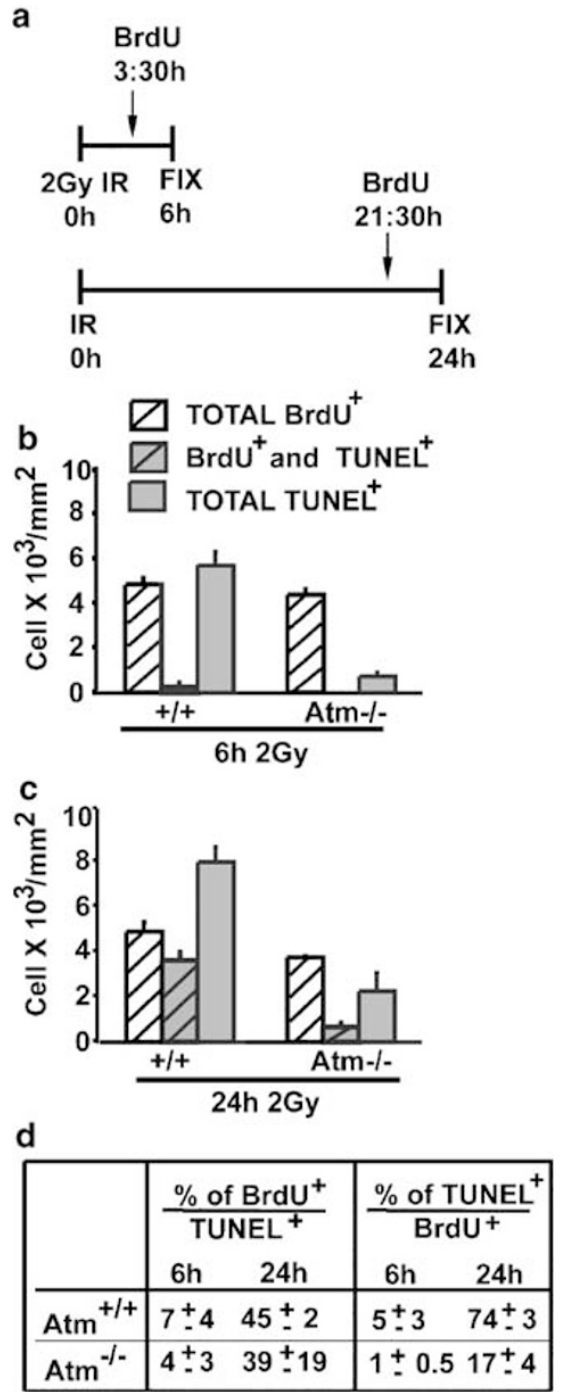

Figure 3 Time of BrdU labeling does not affect the apoptotic response to IR. (a) Experimental protocol for results shown in (b-d). Quantification of $\mathrm{BrdU}^{+}$cells (hatched white bars), cells double-positive for BrdU plus TUNEL (hatched gray bars) and TUNEL ${ }^{+}$cells (gray bars) at $6 \mathrm{~h}$ (b) or $24 \mathrm{~h}$ (c) after $2 \mathrm{~Gy}$ IR with the indicated genotypes. (d) Summary of the percentage of double-positive cells (BrdU plus TUNEL) relative to TUNEL ${ }^{+}$cells or relative to $\mathrm{BrdU}^{+}$cells with the indicated genotypes retinas (Figure 3). Thus, IR-induced apoptosis of proliferating neuroblasts (PCNA ${ }^{+}$or $\mathrm{BrdU}^{+}$) was much reduced in $\mathrm{Atm}^{-l-}$ retinas. Apoptosis of postmitotic cells also required Atm; this is inferred from the similar ratio of $\mathrm{PCNA}^{+}$and $\mathrm{PCNA}^{-}$cells in the residual TUNEL ${ }^{+}$populations found in the $\mathrm{Atm}^{-1-}$ retinas (Figure 2c). Therefore, Atm is required for IR to induce apoptosis in both proliferating neuroblasts and undifferentiated postmitotic cells of the developing retinas.

The essential role of p53 in IR-induced apoptosis is well established. As expected, IR-induced apoptosis is completely abolished in $\operatorname{Trp}_{53} 3^{-1-}$ retinas (Figure 4). We also observed a significant reduction of apoptosis in Trp53 heterozygous mutant retinas (Figure $4 a$ and $b$, Table 1). The residual apoptotic response in the $\operatorname{Trp}_{5} 3^{+/-}$retinas exhibited the same two-wave characteristics as the $\operatorname{Trp} 53^{+/+}$retinas. The

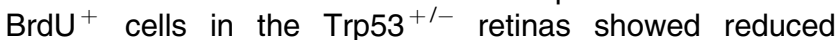
apoptotic response to $2 \mathrm{~Gy}$ of IR (Figure 4c). Among the residual $\mathrm{TUNEL}^{+}$cells in the $\mathrm{Trp}^{+} 3^{+l-}$ retinas, the $\mathrm{BrdU}^{+}$ fraction was similar to that of the $+/+$ littermate retinas (Figure 4c), showing apoptosis of $\mathrm{BrdU}^{-}$cells to also be reduced in the Trp53 ${ }^{+/-}$retinas. Thus, a Trp53 gene dosage effect exists in the retinal apoptosis induced by 2 Gy of IR.

Ex vivo culture with $1 \mu \mathrm{M}$ UCN-01 induced similar levels of apoptosis in unirradiated explants of $\operatorname{Trp} 53^{+/+}, \operatorname{Trp} 53^{+/-}$ and $\operatorname{Trp} 53^{-/-}$retinas (Figure $4 \mathrm{~d}$ ), demonstrating UCN-01induced death to be p53 independent. The treatment of irradiated retinal explants with UCN-01 caused a synergistic increase in the apoptotic response of $+/+$ and Trp53 $3^{+/-}$ background, but not in the Trp53 $3^{-1-}$ background (Figure $4 d$ ). UCN-01 can abolish IR-induced G2/M checkpoint and this may account for its ability to enhance IR-induced apoptosis. ${ }^{32-34}$ We observed a strong induction of p21Cip1 by IR in the developing retinas (not shown). However, Cdkn1a (p21Cip1) knockout did not affect IR-induced apoptosis in the developing retinas (Figure 4e). Thus, p21 exerts no antiapoptotic function in this experimental system. The retinas from two other knockout mice, $\mathrm{Mlh}^{-1-}$ and $\mathrm{Abl1}{ }^{-1-}$, also showed a normal apoptotic response to $2 \mathrm{~Gy}$ of IR when compared to the respective wild-type littermate (data not shown). While Mlh1 and c-Abl have been implicated in cisplatin-induced apoptosis, ${ }^{20,21,35}$ they do not appear to play a role in the retinal apoptotic response to IR.

The ATM kinase phosphorylates p53 at Ser15 (murine p53 Ser18). ${ }^{15,16,25}$ Mice with a knock-in mutation of Ser18 to Ala $\left(\operatorname{Trp} 53^{\mathrm{S} 18 \mathrm{~A}}\right)$ have been generated; their thymocytes showed a $50 \%$ reduction in apoptosis induced by a range of IR (2$20 \mathrm{~Gy}){ }^{36}$ E1A-immortalized fibroblasts from Trp53 ${ }^{\mathrm{S} 18 \mathrm{~A} / \mathrm{S} 18 \mathrm{~A}}$ embryos also exhibited a $50 \%$ reduction in apoptotic response to $5 \mathrm{~Gy}$ of IR. ${ }^{37}$ IR-induced apoptosis in thymocytes is mostly Atm independent. ${ }^{11,38,39}$ Therefore, we examined the effect of the Ser18 mutation in our experimental system. When compared to $\operatorname{Trp}_{53} 3^{+/+}$littermates, retinas from the $\operatorname{Trp53}{ }^{\mathrm{S} 18 \mathrm{~A} / \mathrm{S} 18 \mathrm{~A}}$ mice exhibited a much reduced apoptotic response to 2 Gy of IR (Figure 5). At $6 \mathrm{~h}$ post-IR, the number of TUNEL $^{+}$cells was one-tenth that of the $+/+$littermates. At $24 \mathrm{~h}$ post-IR, apoptotic response in the $\operatorname{Trp} 53^{\mathrm{S} 18 \mathrm{~A} / \mathrm{S} 18 \mathrm{~A}}$ retinas was one-fifth that of the $+/+$ littermates (Figure 5, Table 1). The S18A allele also exhibited a gene dosage effect on IRinduced apoptosis, with the $\operatorname{Trp} 53^{+/ \mathrm{S} 18 \mathrm{~A}}$ retinas showing an intermediate level of cell death (Figure 5, Table 1). 

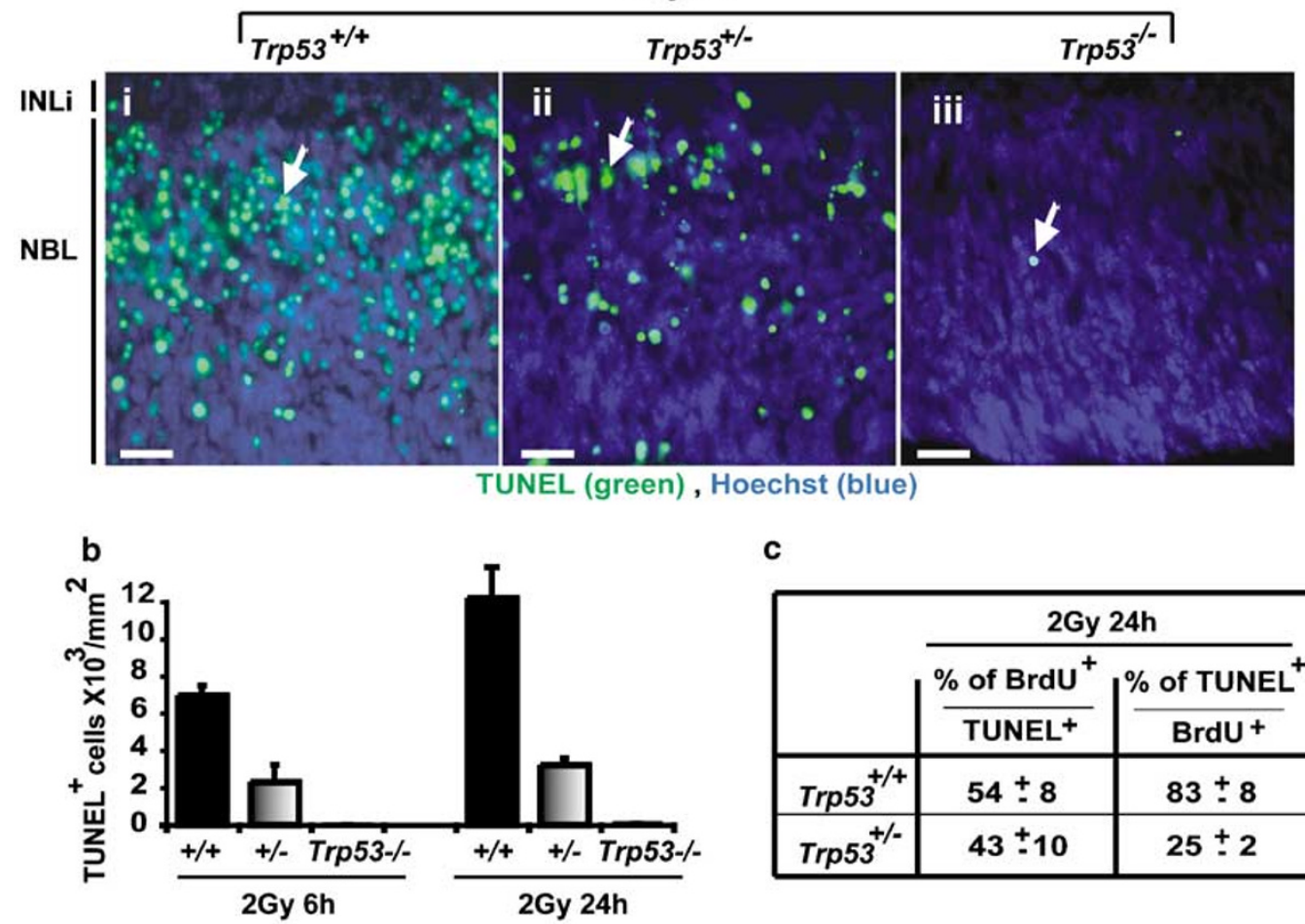

c
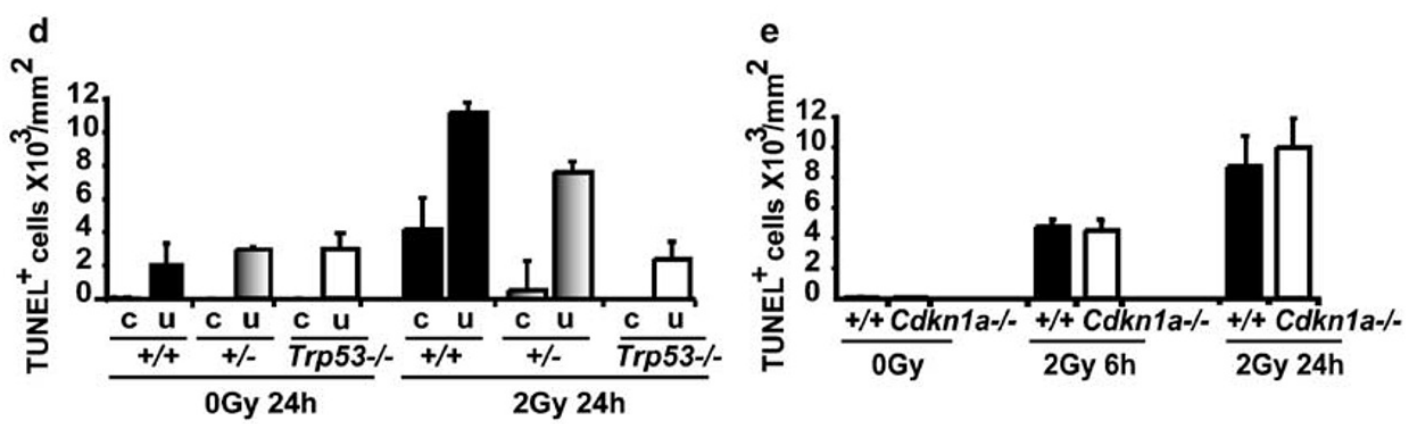

Figure 4 Trp53-haploid insufficiency in the apoptotic response to 2 Gy of IR. (a) Photomicrographs of retinal sections from Trp53 $3^{+1+}$ (i), $\operatorname{Trp53}^{+1-}$ (ii) and Trp53 ${ }^{-1-}$ (iii) stained with TUNEL (green, arrows) and counterstained with Hoechst (blue) $24 \mathrm{~h}$ following 2 Gy. Scale bar $=20 \mu \mathrm{m}$. (b) Quantification of TUNEL ${ }^{+}$cells in retinas from mice (P1-P3) at 6 and $24 \mathrm{~h}$ after 2 Gy, with the following genotypes: Trp53 ${ }^{+1+}$ (black bars), Trp53 ${ }^{+1-}$ (gray bars) and Trp53 $3^{-1}$ (white bars). (c) Summary of the percentage of double-positive cells (BrdU plus TUNEL) relative to the TUNEL ${ }^{+}$cells or relative to BrdU ${ }^{+}$cells. (d) Quantification of TUNEL ${ }^{+}$cells from retinal explants with the indicated genotypes. Retinal explants from P1 mice were kept in the control medium (c) or in the presence of $1 \mu \mathrm{M}$ of $\mathrm{UCN}-01$ (u) for $24 \mathrm{~h}$ with or without prior in vivo IR (2 Gy). (e) Quantification of TUNEL ${ }^{+}$cells in mice retinas (P1-P3) from Cdkn1a ${ }^{+/+}$(black bars) and Cdkn1 ${ }^{-/-}$(white bars) either without IR (0 Gy) or at $6 \mathrm{~h}$ and $24 \mathrm{~h}$ following $2 \mathrm{~Gy}$ IR.

Most studies on IR-induced apoptosis have used higher doses, that is, 10-20 Gy, because 2 Gy of IR seldom triggers apoptosis. Exposure of postnatal day one $(\mathrm{P} 1)$ or $\mathrm{P} 2$ retinas to $14 \mathrm{~Gy}$ of IR caused excessive cell death within $24 \mathrm{~h}$, making it difficult to quantify accurately apoptosis in the $+/+$ retinas (not shown). We therefore irradiated P3-P4 mice with $14 \mathrm{~Gy}$ and counted TUNEL ${ }^{+}$cells in the retinas at $24 \mathrm{~h}$ post-IR

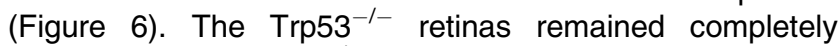
resistant, and the $\mathrm{Atm}^{-1-}$ retinas continued to show partial resistance to $14 \mathrm{~Gy}$-induced apoptosis. This was consistent with previously published results with $14 \mathrm{~Gy}$ IR-induced apoptosis in the CNS from E12.5-P5 mice. ${ }^{11,40}$ Apoptosis in the $\operatorname{Trp} 53^{+/-}$retinas was comparable to the $+/+$littermates following 14 Gy (Figure 6). Thus, a single allele of Trp53 is sufficient for apoptosis to this dose of IR. The S18A/S18A retinas exhibited a nearly normal $(70 \%$ of $+/+)$ apoptotic response to 14 Gy (Figure 6, Table 1), showing phosphorylation of p53 at this serine site to be dispensable at this dose of IR.

When the apoptosis results from $\mathrm{P} 3$ retinas exposed to 2 or 14 Gy of IR were compared, we found the radiation dose effect to be maintained. Therefore, the different response of $\operatorname{Trp}_{53} 3^{+/-}$and $\operatorname{Trp} 53^{\mathrm{S} 18 \mathrm{~A} / \mathrm{S} 18 \mathrm{~A}}$ retinas was determined by the IR dose and not the age of the retinas. A comparative summary of the results from a large cohort of mice is provided in Table 1. 
a

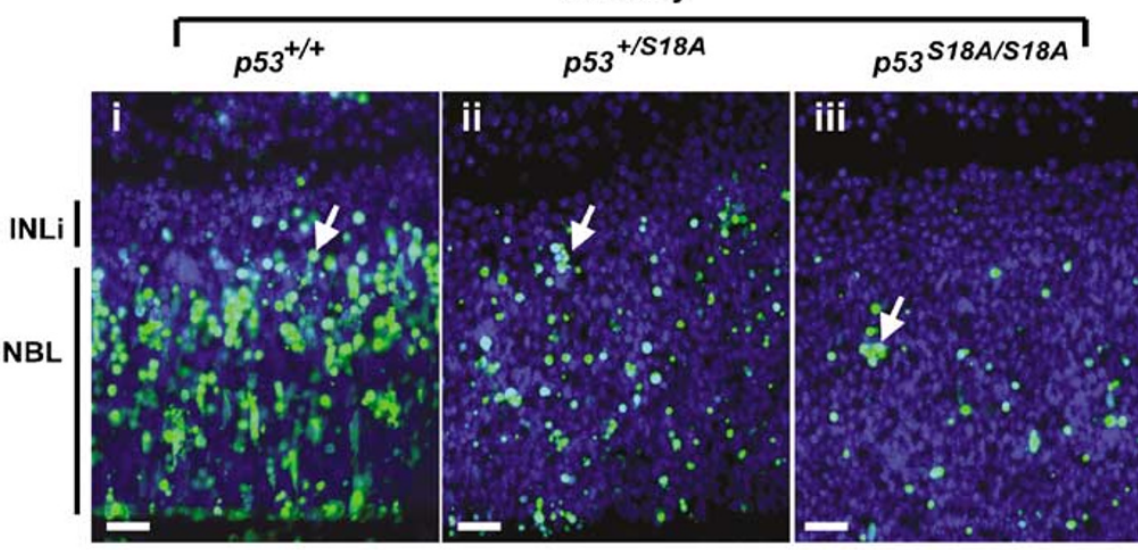

Hoescht (blue), TUNEL (green)

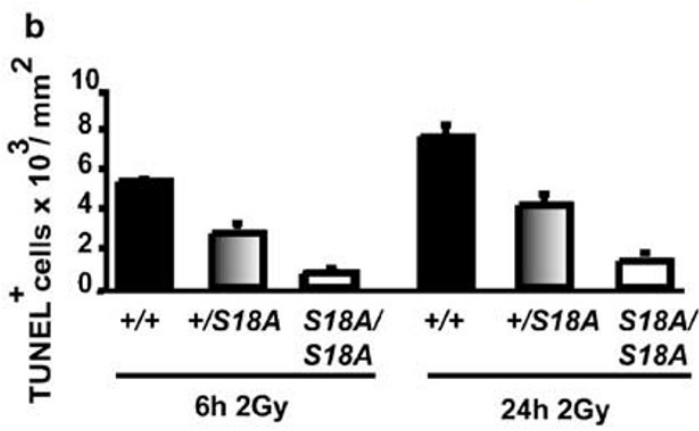

Figure 5 Atm phosphorylation site in p53 is required for apoptotic response to 2 Gy IR. (a) Photomicrographs stained with TUNEL (green, arrows) and counterstained with Hoechst (blue) at $24 \mathrm{~h}$ after $2 \mathrm{~Gy}$ from littermates with the following genotypes: Trp53 ${ }^{+/+}$(i), Trp53 ${ }^{+/ \mathrm{S} 18 \mathrm{~A}}$ (ii) and $\operatorname{Trp53} 3^{\mathrm{S} 18 / \mathrm{S} 18 \mathrm{~A}}$ (iii). Scale bar $=20 \mu \mathrm{m}$. (b) Quantification of TUNEL ${ }^{+}$cells in retinas (P1-P3) at 6 and 24 h post-IR (2 Gy) from Trp53 ${ }^{+1+}$ (black bars), Trp53 ${ }^{+/ S 18 A}$ (gray bars) and Trp53 ${ }^{\text {S18/S18A }}$ (white bars)

\section{Discussion}

The similar reduction in 2 Gy IR-induced retinal apoptosis in $\mathrm{Atm}^{-1-}$ and $\mathrm{p} 53^{\mathrm{S} 18 \mathrm{~A} / \mathrm{S} 18 \mathrm{~A}}$ retinas supports the conclusion that Atm phosphorylation of p53 at Ser18 is required for the majority of cells in the developing NBL to undergo apoptosis. Ser18 phosphorylation of p53 was significantly reduced in $\mathrm{Atm}^{-1-}$ retinas (not shown), consistent with this conclusion. However, phosphorylation of p53 at Ser18 is not required for $14 \mathrm{~Gy}$ of IR to induce retinal apoptosis, despite the continued requirement for Atm (Table 1). Atm phosphorylates and activates a number of downstream effectors that can also activate p53; ${ }^{8,9,34}$ therefore, it is possible that the requirement of Ser18 phosphorylation for apoptosis can be bypassed. These results suggest that Atm activates the apoptotic function of p53 through alternative pathways, possibly depending on the extent of DNA damage in retinal cells.

The partial apoptotic response of $\operatorname{Trp} 53^{+/-}$and $\operatorname{Trp} 53^{+1}$ $S 18 \mathrm{~A}$ retinas to 2 Gy of IR suggests a threshold of p53 activity to be required for the apoptotic response. The basal level of p53 is low in the developing retinas and IR increases the protein level of p53 and p53S18A (not shown). ${ }^{36}$ We found 14 Gy of IR to cause a higher level of p53 accumulation than 2 Gy of IR (not shown). The accumulation of p53 protein is only but one factor in the activation of p53 function. ${ }^{26,41,42}$ Our results suggest p53 to acquire different levels of activity depending on the IR dose. At $2 \mathrm{~Gy}$, Ser18 phosphorylation is essential to activate p53 and two alleles of Trp53 are needed to reach the threshold p53 activity. At $14 \mathrm{~Gy}, \mathrm{p} 53$ is activated by events that are independent of Ser18 phosphorylation and only one allele of p53 is sufficient to reach the threshold activity. It is of interest to note that the CNS apoptosis of DNA ligase 4deficient mice is rescued in the Trp53 ${ }^{+/-}$background. ${ }^{43}$ Thus, apoptosis induced either by endogenous damage or by low-dose IR appears to require two alleles of Trp53. Whether the Ser18 phosphorylation site is also required for the apoptotic phenotype of Lig4-deficient CNS remains to be determined.

The induction of cell death by DNA damage is thought to result from failure in DNA repair, supported by the observation that high-dose IR is more likely to trigger apoptosis. In the developing retinas, however, a fraction of cells in the NBL undergo apoptosis at $4-6 \mathrm{~h}$ following 2 Gy of IR. The apoptotic response in this population of sensitive cells requires Atm and the Ser18 phosphorylation site in p53. It is possible that these hypersensitive cells lack the repair mechanisms to correct lesions induced by $2 \mathrm{~Gy}$ of IR. Alternatively, these cells may undergo apoptosis in response to irradiation without having to suffer a failure in DNA repair. 
a
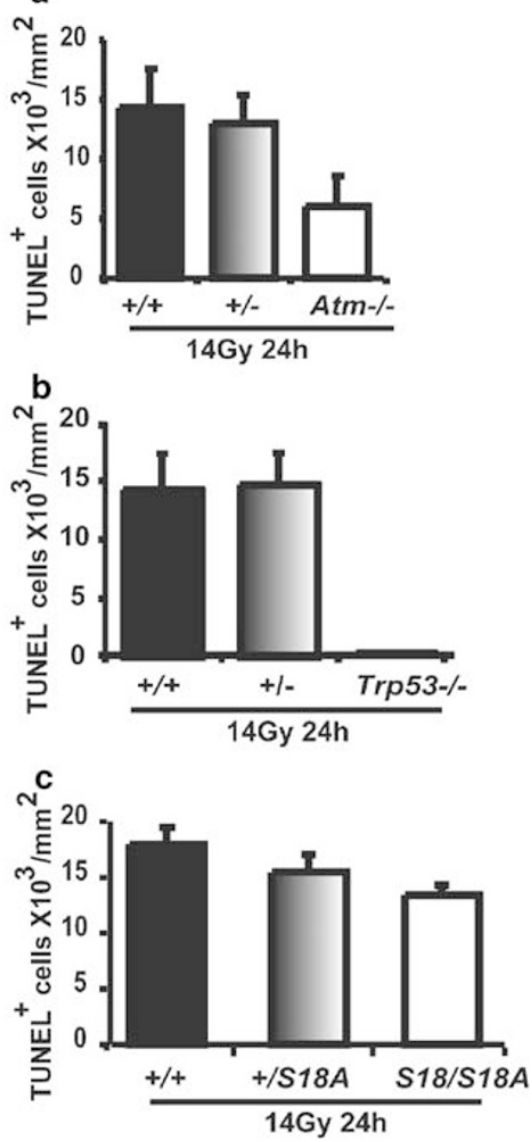

Figure 6 Apoptotic response to $14 \mathrm{~Gy}$ of IR is dependent on p53 and Atm but not on p53 phosphorylation at Ser18. (a-c) Quantification of TUNEL ${ }^{+}$cells in the retina from mice (P3-P4) at $24 \mathrm{~h}$ following $14 \mathrm{~Gy}$ IR. + I+ (black bars), heterozygous (gray bars) and homozygous (white bars), for Atm knockout (a), Trp53 knockout (b) and Trp53 mutation on Ser18 (c). Results were obtained from littermates for each genotype

Table 1 IR dose-dependent apoptotic response in Atm, Trp53 and Trp53 ${ }^{\mathrm{S} 18 \mathrm{~A}}$ retinas

\begin{tabular}{lccc}
\hline Genotype & $\mathbf{6} \mathbf{h}, \mathbf{2}$ Gy & $\mathbf{2 4} \mathbf{h ,} \mathbf{2} \mathbf{G y}$ & $\begin{array}{c}\mathbf{2 4} \mathbf{h}, \\
\mathbf{1 4} \mathbf{G y}\end{array}$ \\
\hline$+/+$ & 1 & 1 & 1 \\
Atm $^{+/-}(n=28)$ & 0.8 & 1 & 0.9 \\
$\operatorname{Trp53}^{18 \mathrm{~A} /+}(n=23)$ & 0.5 & 0.5 & 0.9 \\
$\operatorname{Trp53}^{+/-}(n=13)$ & 0.3 & 0.2 & 1 \\
$\operatorname{Trp53}^{\mathrm{S} 18 \mathrm{~A} / \mathrm{S} 18 \mathrm{~A}}(n=14)$ & 0.1 & 0.2 & 0.7 \\
Atm $^{-/}(n=22)$ & 0.1 & 0.3 & 0.4 \\
$\operatorname{Trp}^{-/-}(n=15)$ & 0 & 0 & 0 \\
$+/+(n=48)$ & 1 & 1.5 & 2.8 \\
\end{tabular}

Relative level of TUNEL ${ }^{+}$cells in each genotype after 2 and 14 Gy of IR. The level of cell death in $+/+$ littermates of each genotype at each time or dose of IR was set at 1 . A separate analysis was carried out to compare the dosedependent response among the $+/+$ retinas (bottom line), where the number of TUNEL ${ }^{+}$cells at $6 \mathrm{~h}$ after $2 \mathrm{~Gy}$ was set as 1 . For each genotype, the total number of animals analyzed was given in parenthesis $(n)$.

Since IR is an important tool in cancer treatment, understanding the cellular context that permits 2 Gy of IR to cause a rapid apoptosis may provide insights to enhance the efficacy of radiation therapy.

\section{Materials and Methods}

\section{Animals and irradiation}

Mice were handled according to guidelines from the UCSD Animal Subjects Committee. Heterozygous mice, in the 129 background, were mated to generate wild-type, heterozygous and mutant mice. All experiments were performed using littermate pups. Newborn mice were exposed to whole-body irradiation of 2 or $14 \mathrm{~Gy}$ (at a rate of approximately $1 \mathrm{~min} / \mathrm{Gy}$ ) with a ${ }^{137} \mathrm{Cs}$ irradiator. Following irradiation, the mice were kept warm and then killed at 6 or $24 \mathrm{~h}$.

In some experiments, bromo-deoxy-uridine (BrdU), an analog of thymidine, was injected intraperitoneally (i.p.) $(60 \mathrm{mg} / \mathrm{kg}$ body weight) preor post-IR. To label S-phase cells at the time of IR, BrdU (Sigma, CA, USA) was injected $1 \mathrm{~h}$ before irradiation (Figure $1 \mathrm{~d}$ ). To rule out that BrdU labeling enhances IR-induced DNA damage to cause apoptosis, BrdU was also injected either $3.5 \mathrm{~h}$ for collection at $6 \mathrm{~h}$ or $21.5 \mathrm{~h}$ after IR for collection at $24 \mathrm{~h}$. This protocol allowed us to monitor the DNA synthesis activity in cells that were about to commit to cell death (Figure 3).

\section{Retinal explantation}

Animals were killed without prior IR or immediately following IR; their tails were collected for DNA extraction and genotyping, and their retinas were removed as described previously. ${ }^{44}$ Retinal explants from each animal were plated in medium with or without $1 \mu \mathrm{M}$ UCN-01 (Drug Synthesis \& Chemistry Branch, Developmental Therapeutics Program, Division of Cancer Treatment and Diagnosis, $\mathrm{NIH}$ ) for $24 \mathrm{~h}$ prior to fixation with $4 \%$ paraformaldehyde.

\section{Histology and immunohistochemistry}

Eyes from killed animals were removed and immediately immersed in fixation buffer (4\% paraformaldehyde in phosphate-buffered saline (PBS), $\mathrm{pH}$ 7.4), and tails were used for DNA extraction and genotyping. Following overnight fixation at $4^{\circ} \mathrm{C}$, whole eyes or retinal explants were infiltrated with $20 \%$ sucrose in PBS for approximately $16 \mathrm{~h}$, and embedded in tissue-

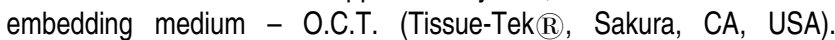
Transverse frozen sections were cut at $10 \mu \mathrm{m}$ in a cryostat. The sections were processed for TUNEL assay according to the manufacturer's protocol (Promega, WI, USA). When double labeling was performed, the retinal sections were boiled in citrate buffer $\mathrm{pH}$ 6.0. After cooling, the slides were first assayed for TUNEL and then blocked with $2 \%$ normal goat serum (NGS) for $30 \mathrm{~min}$, followed by immunostaining with anti-BrdU (RPN 202, Amersham, NJ, USA) or anti-proliferating cell nuclear antigen (antiPCNA, $1: 100$, Calbiochem, CA, USA) for $1 \mathrm{~h}$ in $2 \%$ NGS. After incubation, slides were washed with PBS and incubated with 1:600 goat-anti-mouse Alexa-555 (Promega, WI, USA) in 2\% NGS for $1 \mathrm{~h}$. The nuclei were stained with $1 \mu \mathrm{g} / \mathrm{ml}$ bisbenzimide (Hoechst-332558) (Sigma, CA, USA). After washing, slides were mounted in aqueous mounting medium with antifading agents (Biomeda, CA, USA).

Digital images of retinal sections were collected under $\times 630$ magnification using Image-Pro Plus 4.1 (Media Cybernetics, MD, USA). TUNEL ${ }^{+}, \mathrm{PCNA}^{+}$or $\mathrm{BrdU}^{+}$cells were counted in two fields (field $=0.025 \mathrm{~mm}^{2}$ ) in each of the two eyes from an animal. To avoid variation in the counts due to a difference in developmental stage inside the retinal tissue, the retinal central area (close to the optic nerve), where the retinal tissue develops first, was the location for counting. ${ }^{45,46}$ The results were first analyzed among animals from the same litter. Histograms show the mean plus standard error of the mean (S.E.M.) from three to 11 
animals per genotype. With retinal explants, counting was carried out in two fields per explant and in three randomly chosen explants from each retina. To determine the spatial distribution of apoptotic cells in the INLi and NBL, we divided the image into 10 equal strips parallel to the inner margin of the INLi. Apoptosis was measured in each of these 10 subfields using the Image-pro Plus program. The graphs show the average and S.E.M. from two to three animals in two independent experiments (Figure 1e).

\section{Acknowledgements}

We thank Karen Sang Bui and Irina Hunton for technical support. We appreciate Wang lab members for their critical comments during the preparation of the manuscript. We are grateful to CAPES fellowship (Brazil) for supporting Helena Lobo Borges. Rafael Linden was supported by CNPq, FAPERJ, PRONEX-MCT and a fellowship from The John Simon Guggenheim Foundation. This work was supported by grants from the National Cancer Institute, USA, to JYJW.

\section{References}

1. Zhou BB and Elledge SJ (2000) The DNA damage response: putting checkpoints in perspective. Nature 408: 433-439

2. Friedberg EC (2003) DNA damage and repair. Nature 421: 436-440

3. Rich T, Allen RL and Wyllie AH (2000) Defying death after DNA damage. Nature 407: 777-783

4. Wang JY, Naderi S and Chen TT (2001) Role of retinoblastoma tumor suppressor protein in DNA damage response. Acta Oncol. 40: 689-695

5. Roninson IB (2003) Tumor cell senescence in cancer treatment. Cancer Res. 63: 2705-2715

6. Borges HL and Linden R (1999) Gamma irradiation leads to two waves of apoptosis in distinct cell populations of the retina of newborn rats. J Cell Sci. 112 (Part 23): 4315-4324

7. Shiloh Y (1995) Ataxia-telangiectasia: closer to unraveling the mystery. Eur. J. Hum. Genet. 3: 116-138

8. Shiloh Y (2003) ATM and related protein kinases: safeguarding genome integrity. Nat. Rev. Cancer 3: 155-168

9. Khanna KK, Lavin MF, Jackson SP and Mulhern TD (2001) ATM, a central controller of cellular responses to DNA damage. Cell Death Differ. 8: 10521065

10. Abraham RT (2001) Cell cycle checkpoint signaling through the ATM and ATR kinases. Genes Dev. 15: 2177-2196

11. Herzog KH, Chong MJ, Kapsetaki M, Morgan JI and McKinnon PJ (1998) Requirement for Atm in ionizing radiation-induced cell death in the developing central nervous system. Science 280: 1089-1091

12. Lee $Y$, Barnes DE, Lindahl T and McKinnon PJ (2000) Defective neurogenesis resulting from DNA ligase IV deficiency requires Atm. Genes Dev. 14: 2576 2580

13. Sekiguchi J, Ferguson DO, Chen HT, Yang EM, Earle J, Frank K, Whitlow S, Gu Y, Xu Y, Nussenzweig A and Alt FW (2001) Genetic interactions between ATM and the nonhomologous end-joining factors in genomic stability and development. Proc. Natl. Acad. Sci. USA 98: 3243-3248

14. Bakkenist CJ and Kastan MB (2003) DNA damage activates ATM through intermolecular autophosphorylation and dimer dissociation. Nature 421: 499506

15. Khanna KK, Keating KE, Kozlov S, Scott S, Gatei M, Hobson K, Taya Y, Gabrielli B, Chan D, Lees-Miller SP and Lavin MF (1998) ATM associates with and phosphorylates p53: mapping the region of interaction. Nat. Genet. 20 $398-400$

16. Siliciano JD, Canman CE, Taya Y, Sakaguchi K, Appella E and Kastan MB (1997) DNA damage induces phosphorylation of the amino terminus of p53. Genes Dev. 11: 3471-3481

17. Khosravi R, Maya R, Gottlieb T, Oren M, Shiloh Y and Shkedy D (1999) Rapid ATM-dependent phosphorylation of MDM2 precedes p53 accumulation in response to DNA damage. Proc. Natl. Acad. Sci. USA 96: 14973-14977
18. Maya R, Balass M, Kim ST, Shkedy D, Leal JF, Shifman O, Moas M, Buschmann T, Ronai Z, Shiloh Y, Kastan MB, Katzir E and Oren M (2001) ATM-dependent phosphorylation of Mdm2 on serine 395: role in p53 activation by DNA damage. Genes Dev. 15: 1067-1077

19. Baskaran R, Wood LD, Whitaker LL, Canman CE, Morgan SE, Xu Y, Barlow C, Baltimore D, Wynshaw-Boris A, Kastan MB and Wang JY (1997) Ataxia telangiectasia mutant protein activates c-Abl tyrosine kinase in response to ionizing radiation. Nature 387: $516-519$

20. Wang JY (2000) Regulation of cell death by the Abl tyrosine kinase. Oncogene 19: $5643-5650$

21. Truong T, Sun G, Doorly M, Wang JY and Schwartz MA (2003) Modulation of DNA damage-induced apoptosis by cell adhesion is independently mediated by p53 and c-Abl. Proc. Natl. Acad. Sci. USA 100: 10281-10286

22. Lowe SW, Schmitt EM, Smith SW, Osborne BA and Jacks T (1993) p53 is required for radiation-induced apoptosis in mouse thymocytes. Nature 362 : 847-849

23. Clarke AR, Purdie CA, Harrison DJ, Morris RG, Bird CC, Hooper ML and Wyllie AH (1993) Thymocyte apoptosis induced by p53-dependent and independent pathways. Nature 362: 849-852

24. Lee Y, Chong MJ and McKinnon PJ (2001) Ataxia telangiectasia mutateddependent apoptosis after genotoxic stress in the developing nervous system is determined by cellular differentiation status. J Neurosci. 21: 6687-6693

25. Chao C, Saito S, Anderson CW, Appella E and Xu Y (2000) Phosphorylation of murine $p 53$ at ser-18 regulates the 553 responses to DNA damage. Proc. Natl. Acad. Sci. USA 97: 11936-11941

26. Bargonetti J and Manfredi JJ (2002) Multiple roles of the tumor suppressor p53. Curr. Opin. Oncol. 14: 86-91

27. Hirao A, Kong YY, Matsuoka S, Wakeham A, Ruland J, Yoshida H, Liu D, Elledge SJ and Mak TW (2000) DNA damage-induced activation of $\mathrm{p} 53$ by the checkpoint kinase Chk2. Science 287: 1824-1827

28. Linden R, Rehen SK and Chiarini LB (1999) Apoptosis in developing retinal tissue. Prog. Retin. Eye Res. 18: 133-165

29. Rehen SK, Neves DD, Fragel-Madeira L, Britto LR and Linden R (1999) Selective sensitivity of early postmitotic retinal cells to apoptosis induced by inhibition of protein synthesis. Eur. J. Neurosci. 11: 4349-4356

30. Fujita S (1962) Kinetics of cellular proliferation. Exp. Cell Res. 28: 52-60

31. Dyer MA and Cepko CL (2001) Regulating proliferation during retinal development. Nat. Rev. Neurosci. 2: 333-342

32. Yu L, Orlandi L, Wang P, Orr MS, Senderowicz AM, Sausville EA, Silvestrini R, Watanabe N, Piwnica-Worms H and O'Connor PM (1998) UCN-01 abrogates G2 arrest through a Cdc2-dependent pathway that is associated with inactivation of the Wee1Hu kinase and activation of the Cdc25C phosphatase. J. Biol. Chem. 273: 33455-33464

33. Playle LC, Hicks DJ, Qualtrough D and Paraskeva C (2002) Abrogation of the radiation-induced $\mathrm{G} 2$ checkpoint by the staurosporine derivative UCN-01 is associated with radiosensitisation in a subset of colorectal tumour cell lines. $\mathrm{Br}$. J. Cancer 87: 352-358

34. McGowan $\mathrm{CH}$ (2002) Checking in on Cds1 (Chk2): a checkpoint kinase and tumor suppressor. BioEssays 4: 502-511

35. Gong JG, Costanzo A, Yang HQ, Melino G, Kaelin WG, Levrero M and Wang JY (1999) The tyrosine kinase c-Abl regulates p73 in apoptotic response to cisplatin-induced DNA damage. Nature 399: 806-809

36. Chao C, Hergenhahn M, Kaeser MD, Wu Z, Saito S, Iggo R, Hollstein M Appella $E$ and $X u Y$ (2003) Cell type- and promoter-specific roles of Ser18 phosphorylation in regulating p53 responses. J. Biol. Chem. 278: 41028-41033

37. Woo RA, Jack MT, Xu Y, Burma S, Chen DJ and Lee PW (2002) DNA damageinduced apoptosis requires the DNA-dependent protein kinase, and is mediated by the latent population of p53. EMBO J. 21: 3000-3008

38. Elson A, Wang Y, Daugherty CJ, Morton CC, Zhou F, Campos-Torres $J$ and Leder P (1996) Pleiotropic defects in ataxia-telangiectasia protein-deficient mice. Proc. Natl. Acad. Sci. USA 93: 13084-13089

39. Xu Y and Baltimore D (1996) Dual roles of ATM in the cellular response to radiation and in cell growth control. Genes Dev. 10: 2401-2410

40. Chong MJ, Murray MR, Gosink EC, Russell HR, Srinivasan A, Kapsetaki M, Korsmeyer SJ and McKinnon PJ (2000) Atm and Bax cooperate in ionizing radiation-induced apoptosis in the central nervous system. Proc. Natl. Acad. Sci. USA 97: 889-894 
41. Giaccia AJ and Kastan MB (1998) The complexity of p53 modulation: emerging patterns from divergent signals. Genes Dev. 12: 2973-2983

42. Prives $C$ and Manley JL (2001) Why is p53 acetylated? Cell 107: 815-818

43. Frank KM, Sharpless NE, Gao Y, Sekiguchi JM, Ferguson DO, Zhu C, Manis JP, Horner J, DePinho RA and Alt FW (2000) DNA ligase IV deficiency in mice leads to defective neurogenesis and embryonic lethality via the p53 pathway. Mol. Cell 5: 993-1002
44. Chau BN, Borges HL, Chen TT, Masselli A, Hunton IC and Wang JY (2002) Signal-dependent protection from apoptosis in mice expressing caspaseresistant Rb. Nat. Cell Biol. 4: 757-765

45. Young RW (1985) Cell proliferation during postnatal development of the retina in the mouse. Brain Res. 353: 229-239

46. Rapaport DH and Stone J (1983) The topography of cytogenesis in the developing retina of the cat. J. Neurosci. 3: 1824-1834 